\title{
Prevalence of cytological endometritis and effect on pregnancy outcomes at the time of insemination in nulliparous dairy heifers
}

\author{
O. Bogado Pascottini, ${ }^{* 1}$ M. Hostens, ${ }^{*}$ P. Dini, ${ }^{*}$ M. Van Eetvelde, ${ }^{*}$ P. Vercauteren, $\dagger$ and G. Opsomer* \\ *Department of Reproduction, Obstetrics and Herd Health, Faculty of Veterinary Medicine, Ghent University, Merelbeke 9820, Belgium \\ †CRV Holding BV, Van Thorenburghlaan 14, 9860 Oosterzele, Belgium
}

\begin{abstract}
The objectives of the present study were to assess the prevalence of cytological endometritis (CYTO) at the time of artificial insemination (AI) and its effect on pregnancy outcomes in nulliparous dairy heifers. In total, 512 endometrial cytology samples were taken during AI from 351 nulliparous Holstein-Friesian heifers using cytotape (a 1.5-cm piece of paper tape rolled on the top of an AI catheter covered with a double guard sheet). After sampling, the top of the AI catheter was gently rolled onto a glass slide, air-dried, and stained using Diff-Quick (Fisher Diagnostics, Newark, DE). For each slide, 300 nucleated cells were counted, and the polymorphonuclear cell ratio (\% PMN) was assessed at $400 \times$ magnification. We constructed a receiver operating characteristic curve to find the cutoff point at which sensitivity and specificity (\% PMN) affected pregnancy outcomes. The receiver operating characteristic curve revealed that the threshold level for diagnosing CYTO in nulliparous dairy heifers was $1 \%$ PMN. An insemination was considered successful when pregnancy was confirmed by rectal palpation at least 45 d post-AI. Heifers were considered not pregnant when they received a subsequent insemination or were diagnosed empty by rectal palpation. We built multilevel generalized mixed-effect models to test factors affecting pregnancy outcomes and the occurrence of CYTO at AI. We excluded 16 samples harvested from 12 heifers due to poor sample quality or unavailability of reproductive data. Of the 496 AI samples, the prevalence of CYTO at AI was $7.86 \%(\mathrm{n}=39)$. The conception rate was $62.8 \%(\mathrm{n}=287)$ in CYTO-negative samples $(\mathrm{n}=$ $457)$ and $38.46 \%(\mathrm{n}=15)$ in CYTO-positive samples. Risk factors for non-pregnancy were a previous AI (odds ratio 2.96; 95\% confidence interval: 1.21-7.26) and the interaction between CYTO and previous AI. The only risk factor identified as being associated with the occurrence of CYTO was a previous AI (odds ratio
\end{abstract}

Received April 22, 2016.

Accepted July 27, 2016.

${ }^{1}$ Corresponding author: osvaldo.bogado@ugent.be
4.7; $95 \%$ confidence interval: $2.15-10.34)$. The performance of unsuccessful inseminations significantly affects reproductive outcomes in subsequent AI and may lead to CYTO in nulliparous dairy heifers.

Key words: cytological endometritis, insemination, reproductive outcome

\section{INTRODUCTION}

Ensuring the efficiency of AI involves paying attention to many factors, among them uterine health. It is well known that an adverse uterine environment provokes breakdown of uterine homeostasis, significantly decreasing the reproductive performance of the cow (Gilbert, 1992; Sheldon et al., 2006). Subclinical endometritis is a highly prevalent but asymptomatic uterine disease that can impair a cow's reproductive capacity (Gilbert et al., 2005). In the field, subclinical endometritis is diagnosed primarily by measuring the proportion of inflammatory cells in a cytology sample taken from the uterus and is therefore often referred to as "cytological endometritis" (CYTO; Sheldon et al., 2006; Dubuc et al., 2010a). Cytological endometritis can be diagnosed using the cytobrush (Kasimanickam et al., 2004; Pascottini et al., 2016), low-volume lavage (Gilbert et al., 2005; Pascottini et al., 2016), or cytotape (Pascottini et al., 2015). The main advantages of cytotape are its versatility (enabling sampling at AI or during the luteal phase) and its high-quality samples (Pascottini et al., 2015).

Subclinical endometritis is considered a postpartum disease, presumably associated with endometrial recovery after clinical endometritis, trauma, or other nonmicrobial diseases (Sheldon et al., 2009). However, CYTO samples have not, to our knowledge, been collected in nulliparous heifers to diagnose the condition in this group of animals. Although nulliparous heifers have not been exposed to risk factors for CYTO, such as retained placenta, acute metritis, or severe negative energy balance (Kasimanickam et al., 2004; Dubuc et al., 2010b; Cheong et al., 2011), to date there is no evidence of the presence (or absence) of CYTO in these animals. The objectives of the present paper were to 
assess the prevalence of CYTO and its effect on pregnancy outcomes in nulliparous dairy heifers. We also identified risk factors for the occurrence of CYTO and non-pregnancy following AI.

\section{MATERIALS AND METHODS}

\section{Experimental Design}

A total of 512 AI in Holstein-Friesian nulliparous heifers $(\mathrm{n}=351)$ from 18 commercial dairy herds were included in this prospective observational cohort study, conducted from July 2014 to March 2015 in the Flemish region of Belgium. Participating herds were required to use a computerized record system for herd management. The number of heifers in the herds ranged from 10 to 96 . All heifers were housed in freestall barns and had access to pasture during summer time. Heat was detected based on visual observations. Heifers that were showing signs of standing heat and were clinically healthy (no abnormal vaginal discharge) were included in the study at the time of AI. Heifers that required multiple inseminations before pregnancy occurred were sampled more than once.

One experienced inseminator from the Cattle Improvement Co-operative (CRV, Belgium) performed all inseminations. The farmer informed the inseminator when a heifer was detected in estrus, and inseminations were performed using the a.m./p.m. rule (Nebel et al., 1994). Endometrial cytology samples were obtained at the same time as AI using the newly developed cytotape (Pascottini et al., 2015). Briefly, cytotape consists of a 1.5-cm piece of paper tape (Tesa 4322, Hamburg, Germany) rolled on top of a loaded insemination catheter (Agtech, Manhattan, KS), and covered with a 12-inch-long Sani-Shield rod (Agtech). The cytological sampling and AI procedure was as follows. First, the heifer's vulva was cleaned with a paper towel. Then, the AI catheter (with the cytotape on top) was manipulated through the cervix and, once in the uterine lumen, the catheter was released from the Sani-Shield rod. Next, with some gentle pressure of the index finger through the rectum, the top of the catheter was rotated twice on the dorsal wall of the corpus uteri. Finally, after injecting the semen into the lumen of the uterine body, the AI catheter was covered with the Sani-Shield rod and carefully removed from the genital tract. Microscope glass slides (Marienfeld, Lauda-Königshofen, Germany) were prepared on the farm by rolling the top of the AI catheter on the readable area of the glass slide, homogeneously spreading the collected cellular material. Finally, smears were air-dried and housed in a slide box for storage and transportation.
Slide boxes were delivered every 2 wk to the laboratory facilities. All slides were stained with Diff-Quick (Fisher Diagnostics, Newark, DE), and once the slides were dry, Eukitt mounting medium (O. Kindler GmbH, Freiburg, Germany) was used to protect the specimens and hold the coverslips on the slides. Microscopic evaluation was done at $100 \times$ and $400 \times$ magnifications (Kyowa Optical, Tokyo, Japan) by a single experienced reader. In total, 300 nucleated cells were counted, and the polymorphonuclear cell ratio (\% PMN) was evaluated (Melcher et al., 2014). The total cellularity and quality of the samples were assessed in 10 high-power fields at $100 \times$ (Cocchia et al., 2012; Pascottini et al., $2015)$. Samples were classified as low cellularity $(<50$ cells), moderate cellularity (50-100 cells), and high cellularity ( $>100$ cells); and as poor quality $(<50 \%$ intact cells), good quality (50-75\% intact cells), and very good quality ( $>75 \%$ intact cells).

An insemination was considered successful when pregnancy was confirmed by rectal palpation at least 45 d post-AI. Inseminations were considered unsuccessful when they were followed by another insemination or when the animals were diagnosed as not pregnant by rectal palpation at least $45 \mathrm{~d}$ post-AI.

\section{Statistical Analyses}

Individual heifer data were taken from the data capture forms collected by the inseminator, and from the computerized record system at each farm and exported to Excel (Microsoft Corp., Redmond, WA). Statistical analyses were performed using $\mathrm{R}$ version 3.3.0 (R Inc., Boston, MA), considering the AI sample as the unit of interest.

Before the start of the study, a sample-size calculation was conducted to identify the difference in conception rate between diseased and non-diseased animals, with a 95\% CI and $80 \%$ power (Dohoo et al., 2009). However, because neither the prevalence of CYTO nor the pregnancy risk in affected nulliparous heifers was available, we extrapolated variables that had been described in cows. We used a CYTO prevalence of $30 \%$ (Barański et al., 2012) and considered the conception rate in healthy heifers to be $67 \%$ (Brickell et al., 2009), versus $40.2 \%$ in diseased animals. Cows with CYTO had lower odds [odds ratio (OR): 0.6] of becoming pregnant than healthy cows (Cheong et al., 2011).

For the data set assessment, descriptive statistical analyses were conducted using the summary function of the $\mathrm{R}$ coding system (package base). A receiver operating characteristic (ROC) curve (package pROC; Robin et al., 2011) was constructed to assess the cutoff point where the higher summation of sensitivity and specific- 
ity (\% PMN) negatively affects pregnancy outcomes. To build the ROC curve, pregnancy outcomes for each AI was set as the response variable and the endometrial cytology result (\% PMN) as the predictor. Based on the cutoff point of the ROC curve, we calculated Cohen's kappa coefficient to assess intra-observer agreement in a random subsample of 100 endometrial cytology slides (package caret, function confusionmatrix; Kuhn, 2008).

We built multilevel generalized mixed-effect models to test which explanatory variables significantly affected the presence of CYTO at AI and pregnancy outcomes. We used the function glmer (family = binomial) of the package lme4 (Bates et al., 2015) to construct the models. The fixed effects (explanatory variables) included in the model to evaluate the response variable of pregnancy outcomes were as follows: presence or absence of CYTO; whether the heifer had been previously inseminated or not; whether the heifer had been previously sampled using cytotape or not; bull identification; month of AI; and age (in months) of the heifer (continuous variable). Risk factors tested for CYTO were as follows: whether the heifer was previously inseminated or not; month of AI; and age (in months) of the heifer (continuous variable). All effects with $P$-values $<0.2$ (univariate) and their interactions were included in the final models, and the ultimate model was computed using backward stepwise elimination. For all models, we used the identification of the heifer nested within herd as a random effect. We used this random effect combination because of its better fit compared to other random effects [lowest Akaike and Bayesian information value (Akaike, 1980; Ishiguro and Sakamoto, 1983)]. In the final models, statistical significance was $P<0.05$ (Dohoo et al., 2009).

\section{RESULTS}

Results of the sample-size calculation revealed that a minimum of 496 animals should be sampled. In the end, 512 samples were collected in the present study, of which $99.61 \%(\mathrm{n}=510)$ were considered readable and accepted for further analysis. Samples that were not considered readable generally lacked cells on the slide. Of the readable samples, $85.69 \%(\mathrm{n}=437)$ displayed moderate cellularity, $11.37 \%(\mathrm{n}=58)$ had high cellularity, and 2.94\% ( $\mathrm{n}=15)$ had low cellularity. Most of the readable samples $(98.24 \% ; n=501)$ were of very good quality. Of the rest, $1.76 \%(\mathrm{n}=9)$ were of moderate quality and no samples were of poor quality.

Initially, 351 nulliparous heifers were included in the study. However, 12 heifers (14 samples) were excluded from statistical analysis due to the unavailability of pregnancy results (heifers were culled or sold). The final data set was based on 496 AI samples (339 heifers).
The mean number of AI per heifer was $1.72 \pm 1.06$, and on average $1.45 \pm 0.78$ cytotape samples were obtained per heifer. The overall conception rate was $60.89 \%$ (302 pregnancies from $496 \mathrm{AI}$ samples).

The ROC curve revealed that the threshold level for diagnosing CYTO in nulliparous dairy heifers was $1 \%$ PMN. The sensitivity and specificity for predicting pregnancy at this cutoff were 0.12 and 0.95 , respectively. The area under the curve was 0.54 (95\% CI: 0.51-0.56). The mean \% PMN in the cytology samples was $0.32 \pm$ 1.5 , ranging from 0 to $18 \%$ PMN. Intra-observer agreement for the cytologic evaluation was 0.93 (95\% CI: 0.86-1). Based on the 496 AI samples with acceptable cytology results and reproductive follow-up data, the prevalence of CYTO at AI was $7.86 \%(\mathrm{n}=39)$. The conception rate for CYTO-negative uteruses $(\mathrm{n}=457)$ was $62.8 \%(\mathrm{n}=287)$; for CYTO-positive uteruses $(\mathrm{n}=$ $39)$, it was $38.46 \%(\mathrm{n}=15)$.

More descriptive statistics and interactive data exploration of the analyzed variables can be found at https://public.tableau.com/profile/bovianalytics\#!/ vizhome/OB-Heifers/Published.

Factors affecting AI success are summarized in Tables 1 and 2. In the univariate model, bull identification, previous cytotape sampling, age (in months) of the heifers, and month of AI were not associated with pregnancy outcomes at $P<0.2$ (Table 1) and were not offered to the multivariate model. In the final multivariate model, previous AI (OR 2.96; 95\% CI: 1.21-7.26) and the interaction $\mathrm{CYTO} \times$ previous AI had a negative effect on pregnancy outcomes (Table 2 ). The performance of a previous AI had a significant effect on the prevalence of CYTO (OR 4.7; 95\% CI: $2.15-10.34 ; P<0.0001)$. Other factors, such as age in months and month of AI were not significantly associated with CYTO prevalence.

\section{DISCUSSION}

Subclinical endometritis has been considered a postpartum uterine disease (Sheldon et al., 2009). To the best of our knowledge, this is the first study to evaluate the presence of polymorphonuclear cells in nulliparous heifers from endometrial cytology samples taken at AI, as well as the effect of subclinical endometritis on pregnancy outcomes.

In a previous study, Kaufmann et al. (2009) evaluated the effect of CYTO diagnosed $4 \mathrm{~h}$ after AI (cytobrush) in Holstein-Friesian cows and found no association between pregnancy outcome and \% PMN. It is likely that a postbreeding inflammatory reaction explained the influx of PMN and may have interfered with the cytology results, as has been shown in mares (Troedsson, 1995; Güvenc et al., 2005). Also, high estrogen concentrations 
Table 1. Univariate model of factors affecting AI success in nulliparous dairy heifers, using heifer nested in farm as a random effect

\begin{tabular}{lccc}
\hline Variable & $\begin{array}{c}\text { Odds } \\
\text { ratio }^{1}\end{array}$ & $95 \%$ CI & $P$-value \\
\hline CYTO $^{2}$ & Referent & - & - \\
$\quad$ Negative & 0.37 & $0.18-0.72$ & $0.0042^{3}$ \\
$\quad$ Positive & - & - & $0.22^{4}$ \\
Bulls & & & \\
Previous AI & Referent & - & - \\
No & 0.76 & $0.53-1.11$ & $0.16^{3}$ \\
Yes & & & \\
Previous cytotape sample & Referent & - & - \\
No & 0.93 & $0.62-1.37$ & 0.76 \\
Yes & 1.082 & $0.98-1.19$ & 0.75 \\
Age (mo) & - & - & $0.34^{4}$ \\
Month of AI & - &
\end{tabular}

${ }^{1}$ Odds ratio $(\mathrm{OR})>1(<1)$ is positively (negatively) associated with odds of pregnancy.

${ }^{2} \mathrm{CYTO}=$ cytological endometritis.

${ }^{3}$ Variables offered to the multivariate model.

${ }^{4}$ Overall $P$-value.

during heat may provoke the infiltration of PMN into the endometrium (Ohtani et al., 1993; Subandrio et al., 2000), causing false-positive diagnoses of CYTO. Nevertheless, a more recent experiment (Madoz et al., 2013) suggested that the physiological infiltration of PMN was not related to the stage of the estrous cycle. In the present study, samples were harvested during AI, and most of the samples $(>92 \%)$ showed no PMN. The outcomes of the present study support the finding that the results of sampling during insemination are not affected by physiologic PMN infiltration during estrus or by any other physiologic inflammatory reaction of the endometrium, at least in nulliparous dairy heifers. Sampling during AI (open cervix) was fast, easy, and noninvasive (absence of erythrocytes in the slides), and led to high-quality samples (99\% of readable samples were classified as very good). As well, we proved that sampling during AI is justifiable, because the conception results were in a comparable range to those in similar studies (Donovan et al., 2003; Brickell et al., 2009).

We collected a relatively high number of AI samples in the present study $(\mathrm{n}=512)$, but because of the small number of CYTO-positive uteri $(7.86 \%, \mathrm{n}=39)$, the results should be interpreted with caution. However, this number of samples was enough to prove the effect of CYTO on conception rate (CYTO-negative $62.8 \%$ vs. CYTO-positive $38.4 \%$ ) in nulliparous dairy heifers. As described by Gilbert (2011), an inflammatory milieu in the uterus decreases sperm motility, oocyte maturation, corpus luteum function, and embryonic quality. Taken together, these factors impair successful reproduction at multiple crucial stages, and a decreased conception rate is the final consequence. However, in the final model identifying factors that affected pregnancy outcomes of the insemination, only previous insemination and the interaction of previous AI $\times$ CYTO were significantly associated. Moreover, the prevalence of CYTO and the occurrence of a previous AI had a high positive correlation. When we made multiple comparisons in the previous AI $\times$ CYTO interaction (Table 2), we found a significantly lower conception rate in previously inseminated heifers with CYTO compared with heifers that only had CYTO or only had a previous insemination. As previously mentioned, only 39 samples $(7.86 \%)$ were positive for CYTO. From the 39 CYTO-positive samples, $30(70 \%)$ were taken from heifers that had undergone a previous unsuccessful AI.

Risk factors for CYTO in dairy cows have been well described by several authors (Kasimanickam et al.,

Table 2. Multivariate mixed effects analysis of factors affecting AI success in nulliparous dairy heifers, using heifer nested in farm as a random effect and all possible cytological endometritis (CYTO) $\times$ previous AI interactions

\begin{tabular}{|c|c|c|c|c|c|c|c|}
\hline \multicolumn{5}{|c|}{ Variable } & $\begin{array}{l}\text { Odds } \\
\text { ratio }^{1}\end{array}$ & $95 \%$ CI & $P$-value \\
\hline \multicolumn{5}{|c|}{$\begin{array}{l}\text { CYTO-negative } \\
\text { No previous AI } \\
\text { CYTO } \times \text { previous AI } \\
\text { CYTO } \times \text { previous AI (multiple comparisons) }\end{array}$} & $\begin{array}{l}1.55 \\
2.96 \\
-\end{array}$ & $\begin{array}{c}0.63-3.78 \\
1.21-7.26 \\
-\end{array}$ & $\begin{array}{l}0.33 \\
0.01^{*} \\
0.02^{*}\end{array}$ \\
\hline CYTO & $\mathrm{AI}$ & & CYTO & $\mathrm{AI}$ & & & \\
\hline $\begin{array}{l}\text { No } \\
\text { No } \\
\text { No } \\
\text { No } \\
\text { No } \\
\text { Yes }\end{array}$ & $\begin{array}{l}\text { No } \\
\text { No } \\
\text { No } \\
\text { Yes } \\
\text { Yes } \\
\text { No }\end{array}$ & $\begin{array}{l}\text { vs. } \\
\text { vs. } \\
\text { vs. } \\
\text { vs. } \\
\text { vs. } \\
\text { vs. }\end{array}$ & $\begin{array}{l}\text { No } \\
\text { Yes } \\
\text { Yes } \\
\text { Yes } \\
\text { Yes } \\
\text { Yes }\end{array}$ & $\begin{array}{l}\text { Yes } \\
\text { No } \\
\text { Yes } \\
\text { No } \\
\text { Yes } \\
\text { Yes }\end{array}$ & $\begin{array}{l}1.06 \\
0.55 \\
4.6 \\
0.52 \\
4.32 \\
8.26\end{array}$ & $\begin{array}{l}0.72-1.58 \\
0.12-2.66 \\
1.98-10.7 \\
0.11-2.53 \\
1.83-10.19 \\
1.45-47.27\end{array}$ & $\begin{array}{l}0.75 \\
0.46 \\
0.0004^{*} \\
0.42 \\
0.0009^{*} \\
0.02^{*}\end{array}$ \\
\hline
\end{tabular}

${ }^{1}$ Odds ratio $(\mathrm{OR})>1(<1)$ is positively (negatively) associated with odds of pregnancy.

*Variable significantly affected pregnancy outcomes $(P<0.05)$. 
2004; Dubuc et al., 2010b; Cheong et al., 2011). In nulliparous dairy heifers, however, there is no information about this uterine problem or its associated risk factors. However, the results of the risk factor analysis indicating CYTO as a potential risk factor for nonpregnancy should be interpreted with caution due to the low prevalence of CYTO. More studies including a higher number of heifers are needed to confirm our conclusions with more power. The prevalence of CYTO in heifers inseminated more than once was $16.13 \%$ (n $=30$ ), but in heifers who were not previously inseminated, it was only $3.32 \%(\mathrm{n}=9)$. This finding strongly suggests that CYTO in nulliparous heifers may originate from a previous unsuccessful insemination. It is likely that CYTO can be induced by introducing contaminants during insemination, by the inflammatory response provoked by the inseminated material (semen, diluter, contaminants), or by inseminating heifers that are not truly in heat. Inadequate heat detection, periovulatory hormonal disturbance, or early embryonic loss could all be underlying reasons why insemination is unsuccessful (Gustafsson et al., 1986; Duchens et al., 1995; Båge et al., 2002). It is generally accepted that steroid hormones affect the uterine immune response (Rowson et al., 1953); progesterone suppresses the immune response (Olson et al., 1984; Lewis, 2003) but it is more difficult to establish infections while estrogens are dominant (Del Vecchio et al., 1994). When animals are not in heat (metestrus or early diestrus) when they are inseminated, accidental contaminants or the semen itself may trigger an iatrogenic inflammatory reaction. Practitioners must take special care in sterile manipulation when loading the AI pipette to avoid introduction of contaminating material when it is manipulated through the vulva-vagina-cervix into the uterine lumen, and to inseminate only heifers with an open cervix (estrus). Also, sanitary sheets are highly recommended to avoid iatrogenic contamination of the uterus (Aguilar et al., 2006) during AI, particularly in dairy heifers. However, it is unknown why some heifers were positive for CYTO without having experienced a prior insemination. Contaminants (bacteria, viruses, or both) could have invaded the uterus via an opened cervix during a previous estrus, or the endometrium may have been infected via the peripheral blood by bacteria (e.g., Histophilus somni) or a virus that has a distinct tropism for endometrial cells such as the bovine herpesvirus type 4 virus (Donofrio et al., 2007; Szenci et al., 2016).

Heat stress has been previously noted to have a major effect on fertility, mainly in dairy cows (De Rensis and Scaramuzzi, 2003; Jordan, 2003). Donovan et al. (2003) demonstrated that heifers inseminated in the summer were less likely to conceive at first insemina- tion. However, in the present study, the month in which the AI took place did not affect pregnancy outcome. Unfortunately, samples were acquired only from July 2014 to March 2015, so not all months of the year were included. Consequently, "season" could not be introduced in the model, only month of sampling, although it was not significantly associated with the prevalence of CYTO, or with pregnancy outcomes. In accordance with the results of previous studies (Bar-Peled et al., 1997; Donovan et al., 2003), bull identification and age of the heifer at AI were not associated with pregnancy outcomes. Furthermore, harvesting a cytotape sample during a prior insemination was not significantly associated with the conception rate, confirming that cytotape sampling has no detrimental effect on subsequent fertility.

\section{CONCLUSIONS}

In the present study, approximately $8 \%$ of uteri sampled from nulliparous heifers at the time of insemination had CYTO. Positive samples were associated with lower conception rates compared to their negative counterparts. Previous unsuccessful insemination was associated with lower rates of pregnancy and a higher risk of CYTO. The latter might be regarded as the underlying reason for the impaired fertility results. More field studies that include higher numbers of animals are needed to confirm these results with more power.

\section{ACKNOWLEDGMENTS}

The authors acknowledge all inseminators from Cattle Improvement Co-operative (CRV-Belgium) for their enthusiasm and active collaboration in this study. Special thanks to Paul Sys, who AI sampled all the animals included in this paper. Finally, we thank the participating farmers for their willingness to contribute to this study. Osvaldo Bogado Pascottini was supported by the Mundus Lindo's Project (Erasmus Mundus).

\section{REFERENCES}

Aguilar, J., M. Hanks, D. J. Shaw, R. Else, and E. Watson. 2006. Importance of using guarded techniques for the preparation of endometrial cytology smears in mares. Theriogenology 66:423-430.

Akaike, H. 1980. Likelihood and the Bayes procedure. Trabajos de Estadística y de Investigación Operativa 31:143-166.

Båge, R., H. Gustafsson, B. Larsson, M. Forsberg, and H. RodriguezMartinez. 2002. Repeat breeding in dairy heifers: Follicular dynamics and estrous cycle characteristics in relation to sexual hormone patterns. Theriogenology 57:2257-2269.

Bar-Peled, U., B. Robinzon, E. Maltz, H. Tagari, Y. Folman, I. Bruckental, H. Voet, H. Gacitua, and A. Lehrer. 1997. Increased weight gain and effects on production parameters of Holstein heifer calves that were allowed to suckle from birth to six weeks of age. J. Dairy Sci. 80:2523-2528. 
Barański, W., M. Podhalicz-Dzięgielewska, S. Zduńczyk, and T. Janowski. 2012. The diagnosis and prevalence of subclinical endometritis in cows evaluated by different cytologic thresholds. Theriogenology 78:1939-1947.

Bates, D., M. Maechler, B. Bolker, and S. Walker. 2015. lme4: Linear mixed-effects models using Eigen and S4. R package version 1:1-7. 2014. http://CRAN.R-project.org/package $=$ lme4.

Brickell, J. S., N. Bourne, M. M. McGowan, and D. C. Wathes. 2009. Effect of growth and development during the rearing period on the subsequent fertility of nulliparous Holstein-Friesian heifers. Theriogenology 72:408-416.

Cheong, S. H., D. V. Nydam, K. N. Galvao, B. M. Crosier, and R. O. Gilbert. 2011. Cow-level and herd-level risk factors for subclinical endometritis in lactating Holstein cows. J. Dairy Sci. 94:762-770.

Cocchia, N., O. Paciello, L. Auletta, V. Uccello, L. Silvestro, K. Mallardo, G. Paraggio, and M. P. Pasolini. 2012. Comparison of the cytobrush, cottonswab, and low-volume uterine flush techniques to evaluate endometrial cytology for diagnosing endometritis in chronically infertile mares. Theriogenology 77:89-98.

De Rensis, F., and R. J. Scaramuzzi. 2003. Heat stress and seasonal effects on reproduction in the dairy cow-A review. Theriogenology 60:1139-1151.

Del Vecchio, R. P., D. J. Matsas, S. Fortin, D. P. Sponenberg, and G. S. Lewis. 1994. Spontaneous uterine infections are associated with elevated prostaglandin F2 $\alpha$ metabolite concentrations in postpartum dairy cows. Theriogenology 41:413-421.

Dohoo, I., S. Martin, and H. Stryhn. 2009. Veterinary Epidemiological Research. VER Inc., Charlottetown, PE, Canada.

Donofrio, G., S. Herath, C. Sartori, S. Cavirani, C. F. Flammini, and I. M. Sheldon. 2007. Bovine herpesvirus 4 is tropic for bovine endometrial cells and modulates endocrine function. Reproduction 134:183-197.

Donovan, G. A., F. L. Bennett, and F. S. Springer. 2003. Factors associated with first service conception in artificially inseminated nulliparous Holstein heifers. Theriogenology 60:67-75.

Dubuc, J., T. F. Duffield, K. E. Leslie, J. S. Walton, and S. J. LeBlanc. 2010a. Definitions and diagnosis of postpartum endometritis in dairy cows. J. Dairy Sci. 93:5225-5233.

Dubuc, J., T. F. Duffield, K. E. Leslie, J. S. Walton, and S. J. LeBlanc. 2010b. Risk factors for postpartum uterine diseases in dairy cows. J. Dairy Sci. 93:5764-5771.

Duchens, M., M. Maciel, H. Gustafsson, M. Forsberg, H. RodriguezMartinez, and L. E. Edqvist. 1995. Influence of perioestrous suprabasal progesterone levels on cycle length, estrous behavior and ovulation in heifers. Anim. Reprod. Sci. 37:95-108.

Gilbert, R. O. 1992. Bovine endometritis: The burden of proof. Cornell Vet. 82:11-14

Gilbert, R. O. 2011. The effects of endometritis on the establishment of pregnancy in cattle. Reprod. Fertil. Dev. 24:252-257.

Gilbert, R. O., S. T. Shin, C. L. Guard, H. N. Erb, and M. Frajblat. 2005. Prevalence of endometritis and its effects on reproductive performance of dairy cows. Theriogenology 64:1879-1888.

Gustafsson, H., K. Larsson, H. Kindahl, and A. Madej. 1986. Sequential endocrine changes and behavior during estrus and metestrus in repeat breeder and virgin heifers. Anim. Reprod. Sci. 10:261-273.

Güvenc, K., T. Reilas, and T. Katila. 2005. Effect of insemination dose and site on uterine inflammatory response of mares. Theriogenology 63:2504-2512.

Ishiguro, M., and Y. Sakamoto. 1983. A Bayesian approach to binary response curve estimation. Ann. Inst. Stat. Math. 35:115-137.

Jordan, E. R. 2003. Effects of heat stress on reproduction. J. Dairy Sci. 86(E-Suppl.):E104-E114
Kasimanickam, R., T. F. Duffield, R. A. Foster, C. J. Gartley, K. E. Leslie, J. S. Walton, and W. H. Johnson. 2004. Endometrial cytology and ultrasonography for the detection of subclinical endometritis in postpartum dairy cows. Theriogenology 62:9-23.

Kaufmann, T. B., M. Drillich, B. A. Tenhagen, D. Forderung, and W. Heuwieser. 2009. Prevalence of bovine subclinical endometritis 4h after insemination and its effects on first service conception rate. Theriogenology 71:385-391

Kuhn, M. 2008. Building predictive models in R using the caret package. J. Stat. Softw. 28:1-26.

Lewis, G. S. 2003. Steroidal regulation of uterine resistance to bacterial infection in livestock. Reprod. Biol. Endocrinol. 1:117.

Madoz, L. V., M. J. Giuliodori, M. Jaureguiberry, J. Plontzke, M. Drillich, and R. L. de la Sota. 2013. The relationship between endometrial cytology during estrous cycle and cutoff points for the diagnosis of subclinical endometritis in grazing dairy cows. J. Dairy Sci. 96:4333-4339.

Melcher, Y.. I. Prunner, and M. Drillich. 2014. Degree of variation and reproducibility of different methods for the diagnosis of subclinical endometritis. Theriogenology 82:57-63.

Nebel, R. L., W. L. Walker, M. L. McGilliard, C. H. Allen, and G. S. Heckman. 1994. Timing of artificial insemination of dairy cows: Fixed time once daily versus morning and afternoon. J. Dairy Sci. $77: 3185-3191$

Ohtani, S., K. Okuda, K. Nishimura, and S. Mohri. 1993. Histological changes in bovine endometrium during the estrous cycle. Theriogenology 39:1033-1042.

Olson, J. D., L. Ball, R. G. Mortimer, P. W. Farin, W. S. Adney, and E. M. Huffman. 1984. Aspects of bacteriology and endocrinology of cows with pyometra and retained fetal membranes. Am. J. Vet. Res. 45:2251-2255.

Pascottini, O. B., P. Dini, M. Hostens, R. Ducatelle, and G. Opsomer 2015. A novel cytologic sampling technique to diagnose subclinical endometritis and comparison of staining methods for endometrial cytology samples in dairy cows. Theriogenology 84:1438-1446.

Pascottini, O. B., M. Hostens, P. Dini, J. Vandepitte, R. Ducatelle, and G. Opsomer. 2016. Comparison between cytology and histopathology to evaluate subclinical endometritis in dairy cows. Theriogenology 86:1550-1556

Robin, X., N. Turck, A. Hainard, N. Tiberti, F. Lisacek, J. C. Sanchez, and M. Muller. 2011. proc: An open-source package for R and S+ to analyze and compare ROC curves. BMC Bioinformatics 12:77.

Rowson, L. E., G. E. Lamming, and R. M. Fry. 1953. Influence of ovarian hormones on uterine infection. Nature 171:749-750.

Sheldon, I. M., J. Cronin, L. Goetze, G. Donofrio, and H. J. Schuberth. 2009. Defining postpartum uterine disease and the mechanisms of infection and immunity in the female reproductive tract in cattle. Biol. Reprod. 81:1025-1032.

Sheldon, I. M., G. S. Lewis, S. LeBlanc, and R. O. Gilbert. 2006 Defining postpartum uterine disease in cattle. Theriogenology $65: 1516-1530$

Subandrio, A. L., I. M. Sheldon, and D. E. Noakes, 2000 Peripheral and intrauterine neutrophil function in the cow: The influence of endogenous and exogenous sex steroid hormones. Theriogenology $53: 1591-1608$

Szenci, O., G. Sassi, L. Fodor, L. Molnár, Z. Szelényi, J. Tibold, I. Mádl, and L. Egyed. 2016. Co-infection with bovine herpesvirus 4 and Histophilus somni significantly extends the service period in dairy cattle with purulent vaginal discharge. Reprod. Domest. Anim. 51:143-149.

Troedsson, M. 1995. Uterine response to semen deposition in the mare. Pages 130-135 in Proc. Soc. Theriogenology. San Antonio, TX. 